\title{
Facile synthesis of mesoporous silica nanoparticles and its electrochemical conversion of $\mathrm{CO}_{2}$ to fuels
}

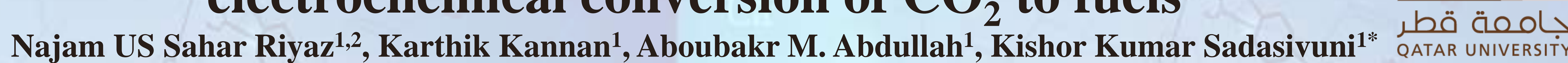

\author{
Center for Advanced Materials, Qatar University, P.O. Box 2713, Doha, Qatar \\ ${ }^{2}$ Chemistry and Earth Sciences, Qatar University, P.O. Box 2713, Doha, Qatar \\ *kishorkumars@qu.edu.qa
}

\section{ABSTRACT}

The increasing amount of $\mathrm{CO}_{2}$ emissions from the industries is proving to have disastrous consequences on the environment. It would be highly beneficial if this $\mathrm{CO}_{2}$ is to be recycled and converted into useful fuel. The aim of this project involves synthesizing a suitable catalyst which can be used for the electrochemical (EC) conversion of $\mathrm{CO}_{2}$ to fuel. The developed catalyst should be mesoporous silica nanoparticles and loaded on to a metal oxide surface. The synthesis involved a relatively simple procedure of forming a homogenous mixture for the nanoparticles, drying the mixture for 2 days then loading on to the metal nitrate. Finally, multiple scans and tests were run on the synthesized sample to characterize its qualities. The results show that the synthesized mesoporous silica nanoparticles have suitable catalytic properties for electrochemical reduction of $\mathrm{CO}_{2}$ to fuel.

\section{INTRODUCTION}

Mesoporous materials have a high surface area and a narrow pore size. Mesoporous silica has a honey-comb structure which allows for a greater surface area of adsorption in catalysis.

The need for an efficient catalyst for the photoelectrochemical conversion of $\mathrm{CO}_{2}$ is extremely dire to efficiently reduce the emissions of $\mathrm{CO}_{2}$ in the industry.

The mesoporous silica nanoparticles can be coated with metal nitrates or metal oxides to enhance the catalytic properties. These metal oxides usually consist of particles less than $100 \mathrm{~nm}$ in size and are widely used for catalytic applications.

\section{METHODOLOGY}

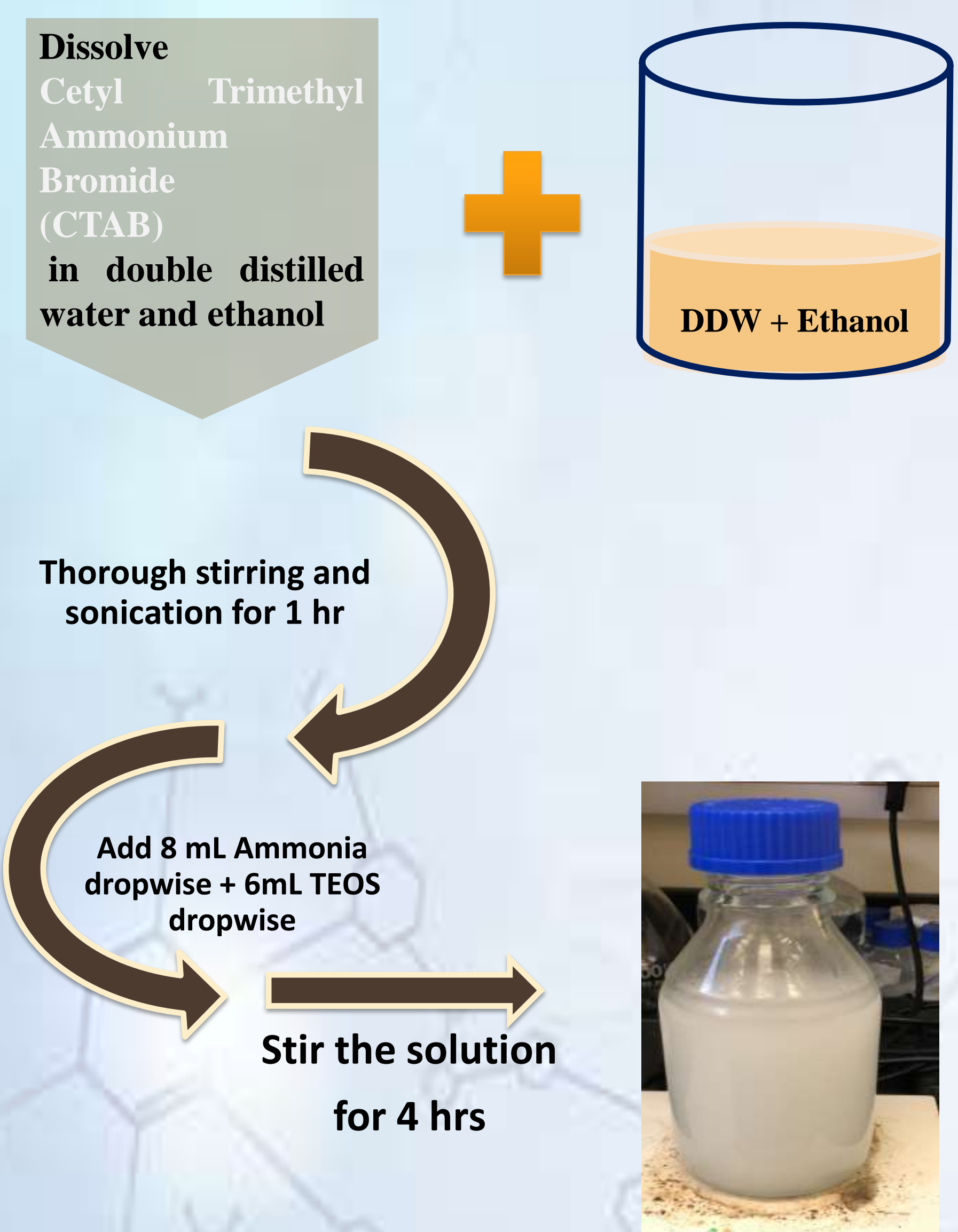

Appearance of final solution

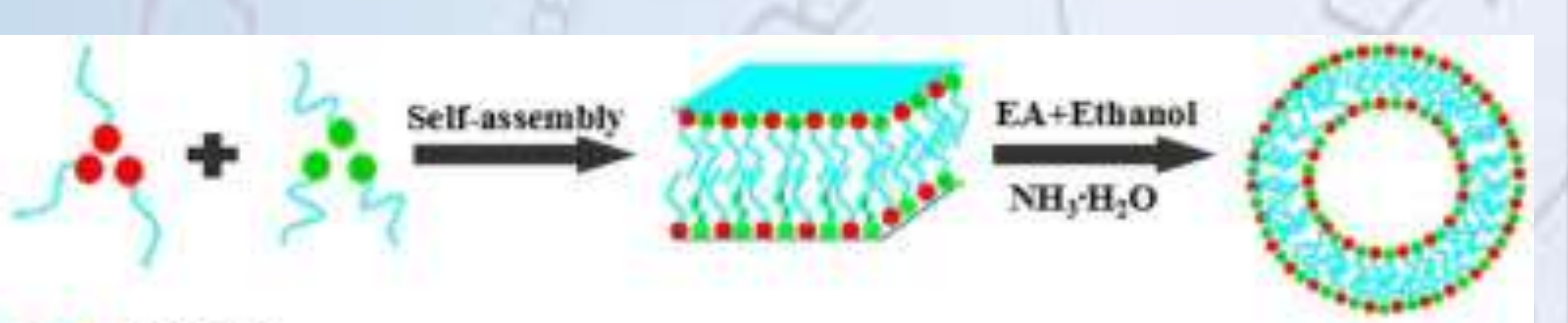

- CTAB

- SDBS

TEOS
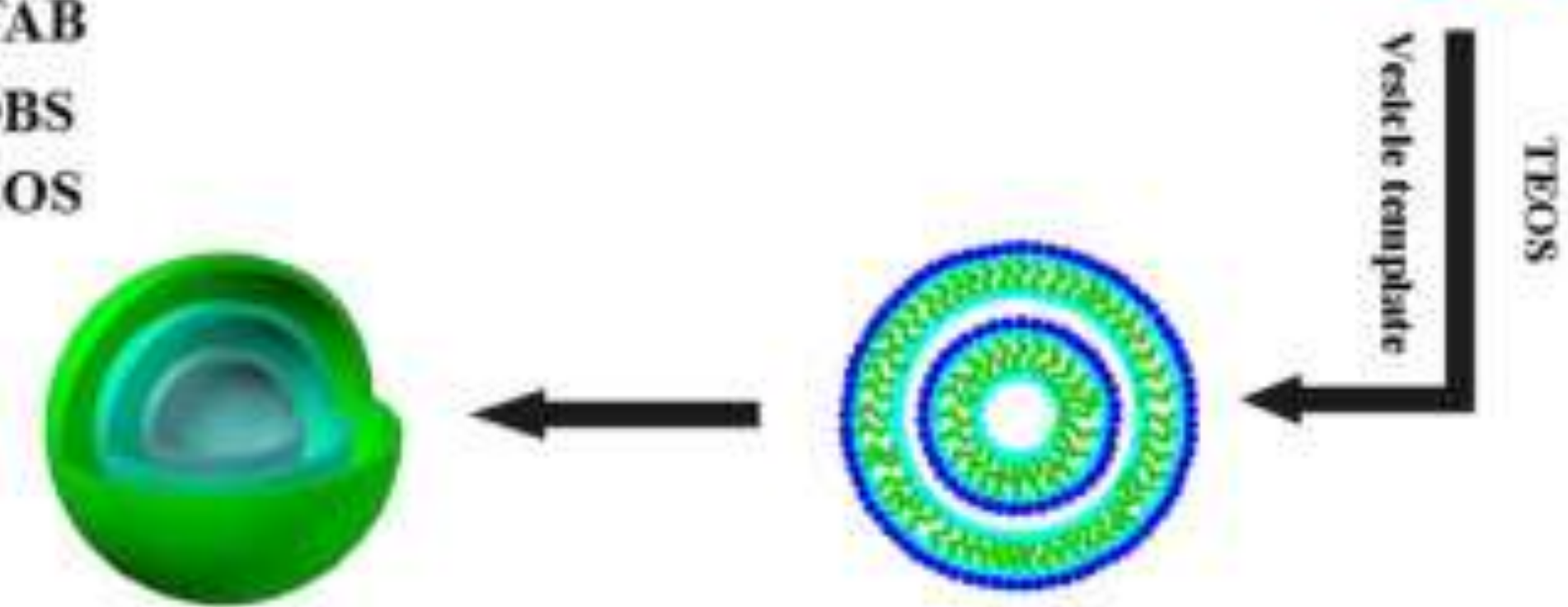

The solution was dried at $120^{\circ} \mathrm{C}$

The powder was then grinded

$\checkmark$ Finally, the sample was calcinated at $550^{\circ} \mathrm{C}$ for 5 hrs.

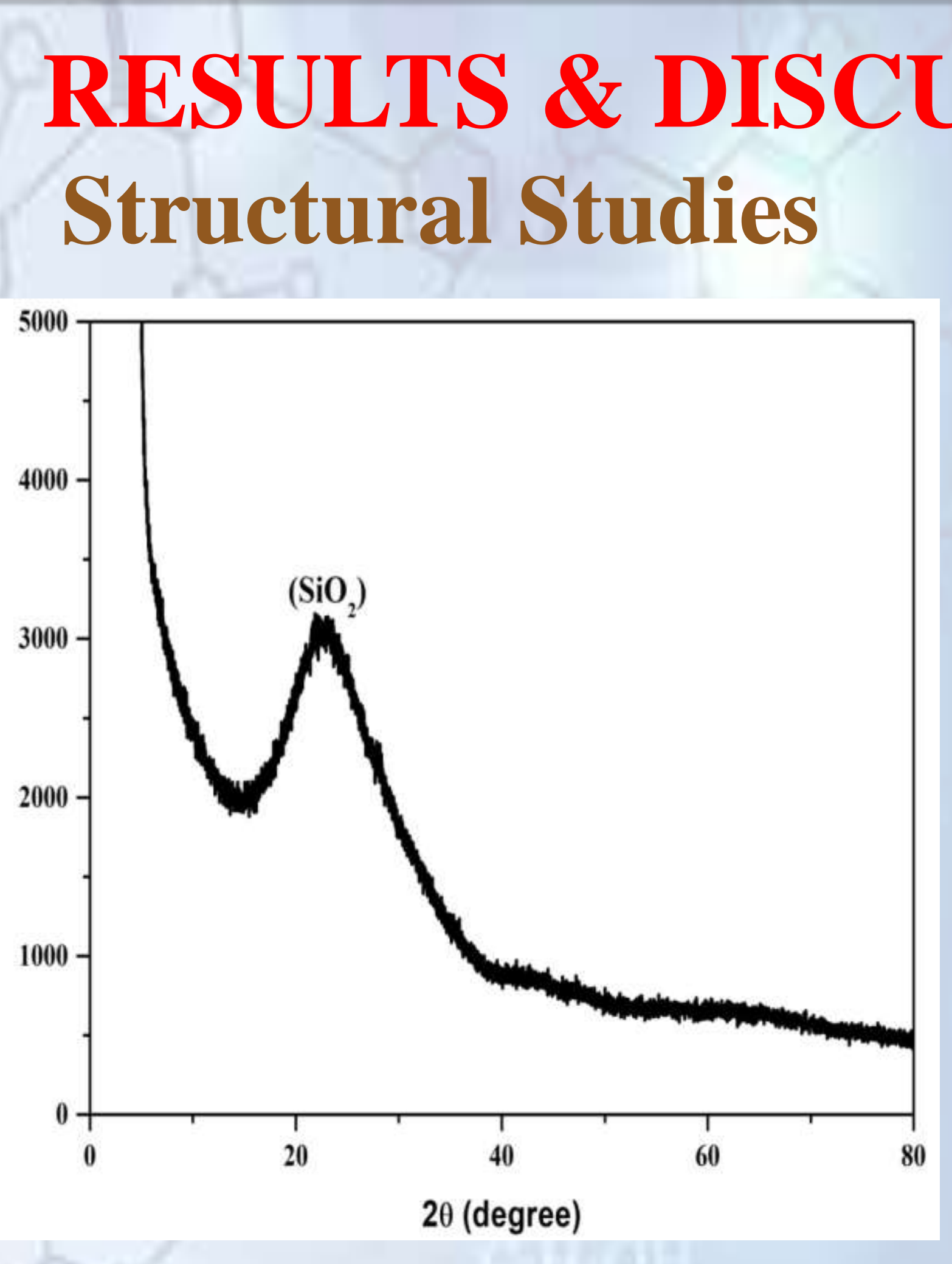

Results from X-Ray Diffraction showing th presence of Silica Dioxide at 22.07 degrees
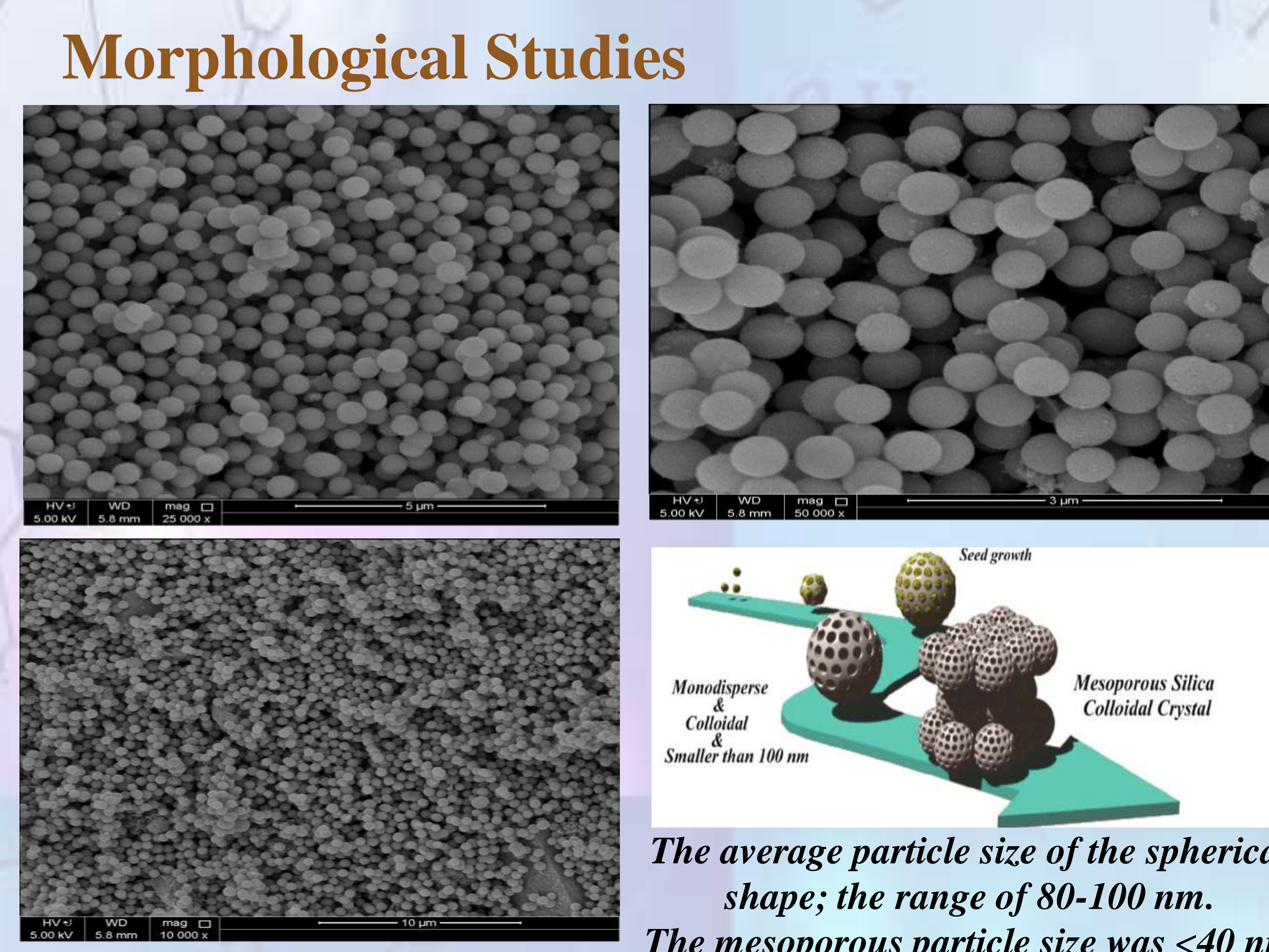

The average particle size of the spherica shape; the range of 80-100 $\mathrm{nm}$. The mesoporous particle size was $<40 \mathrm{~nm}$

Scanning Electron Microscopy results showing the mesoporous silica nanoparticles
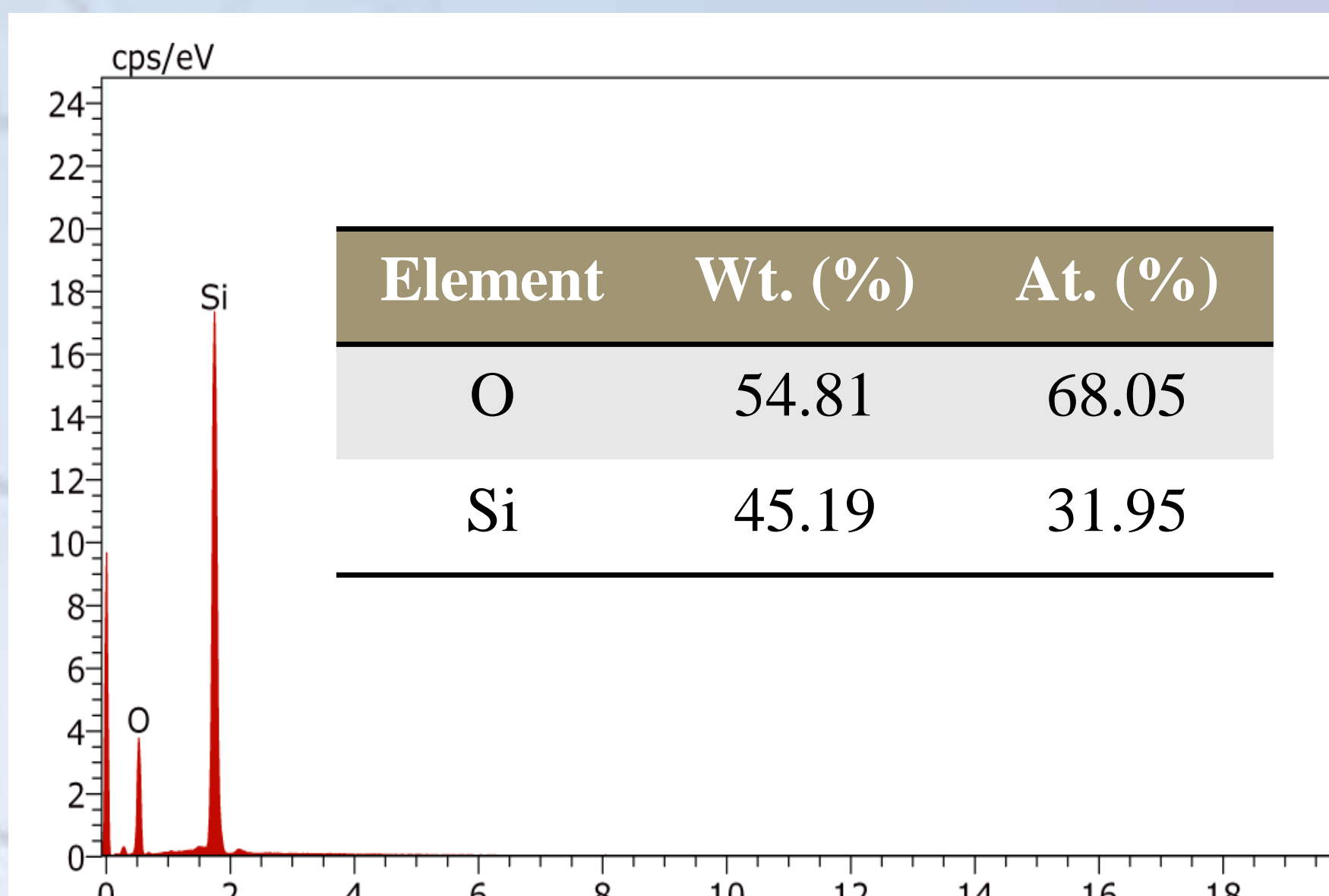

EDAX results showing the presence of only silicon and oxide, thus proving the purity of the synthesized sample.

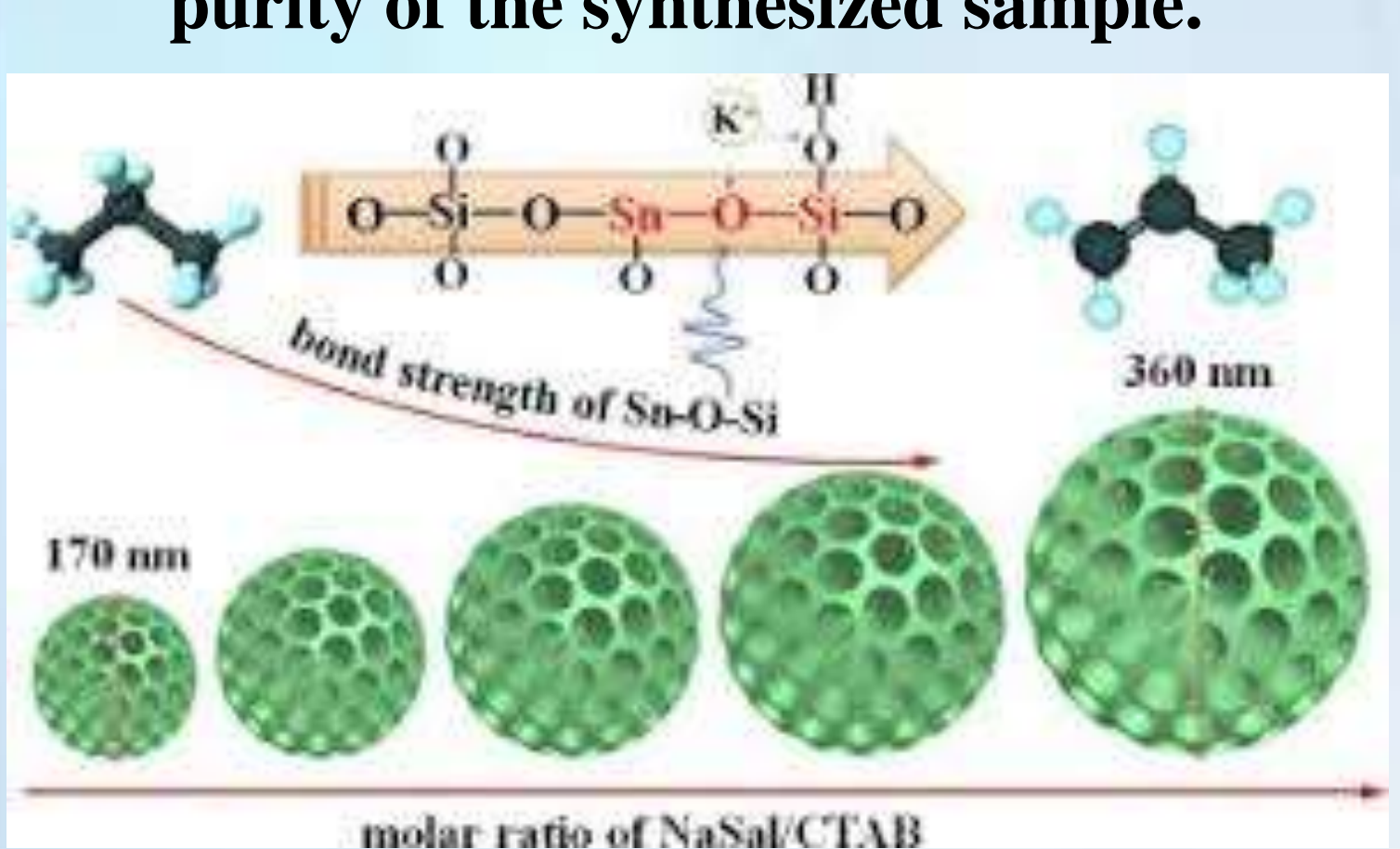

Electrochemical properties

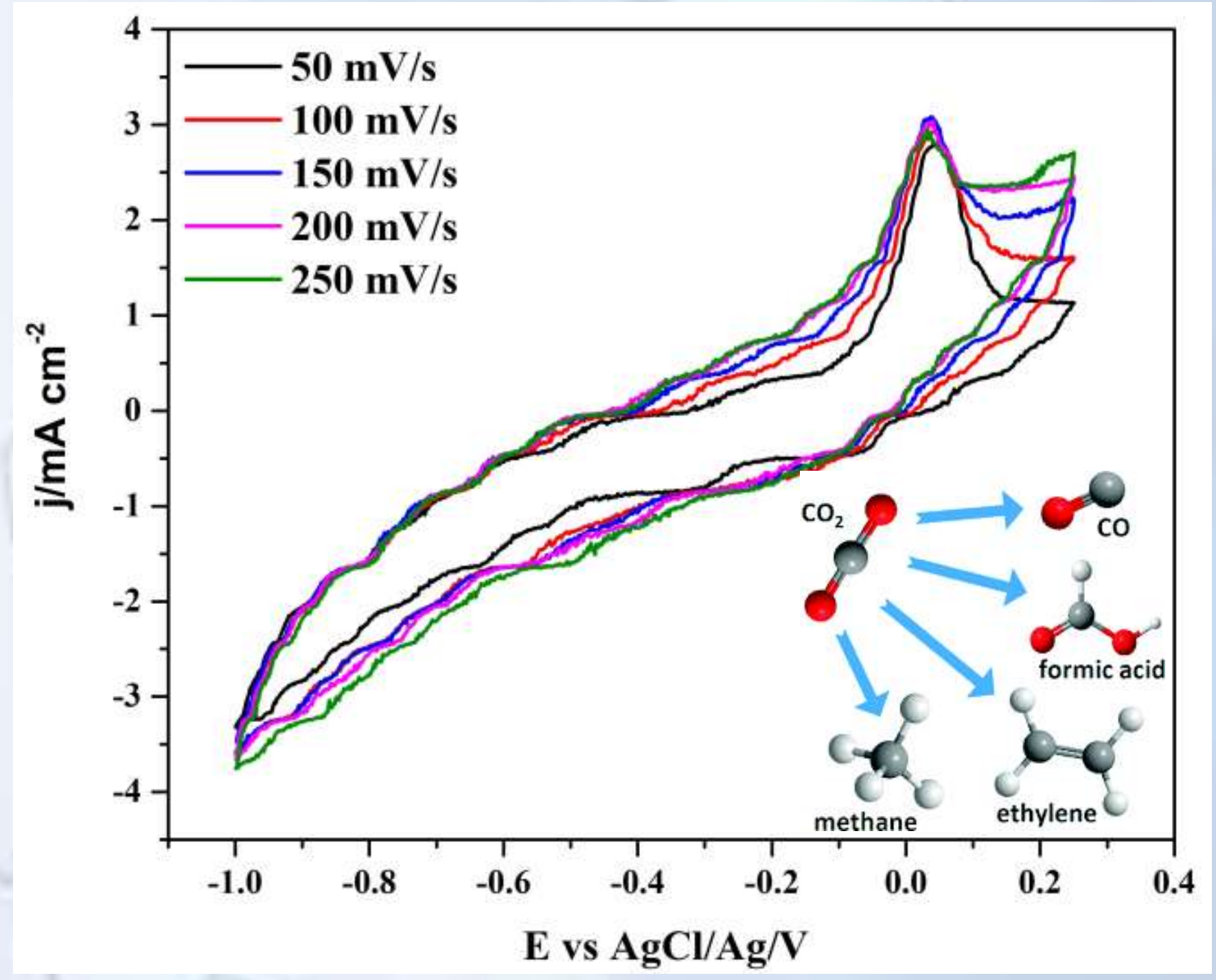

CV Studies of Mesoporous Silica nanoparticles in a $\mathrm{CO}_{2}$ saturated aqua solution of $0.5 \mathrm{M} \mathrm{NaOH}$ at different scan rates

\begin{tabular}{cc}
\hline Scan Rate & $\begin{array}{c}\text { Current Density } \\
\left(\mathrm{mA} / \mathrm{cm}^{2}\right)\end{array}$ \\
\hline 50 & 3.297 \\
100 & 3.47 \\
150 & 3.576 \\
200 & 3.619 \\
250 & 3.725 \\
\hline
\end{tabular}

EIS studies of prepared mesoporous silica nanoparticles in the presence of $\mathrm{CO}_{2}$ measured in $0.5 \mathrm{M} \mathrm{NaOH}$ under an applied potential of $0.2 \mathrm{~V}$ at room temperature.

The charge transfer property of mesoporous silica nanoparticles - outstanding performance - outstanding performanc

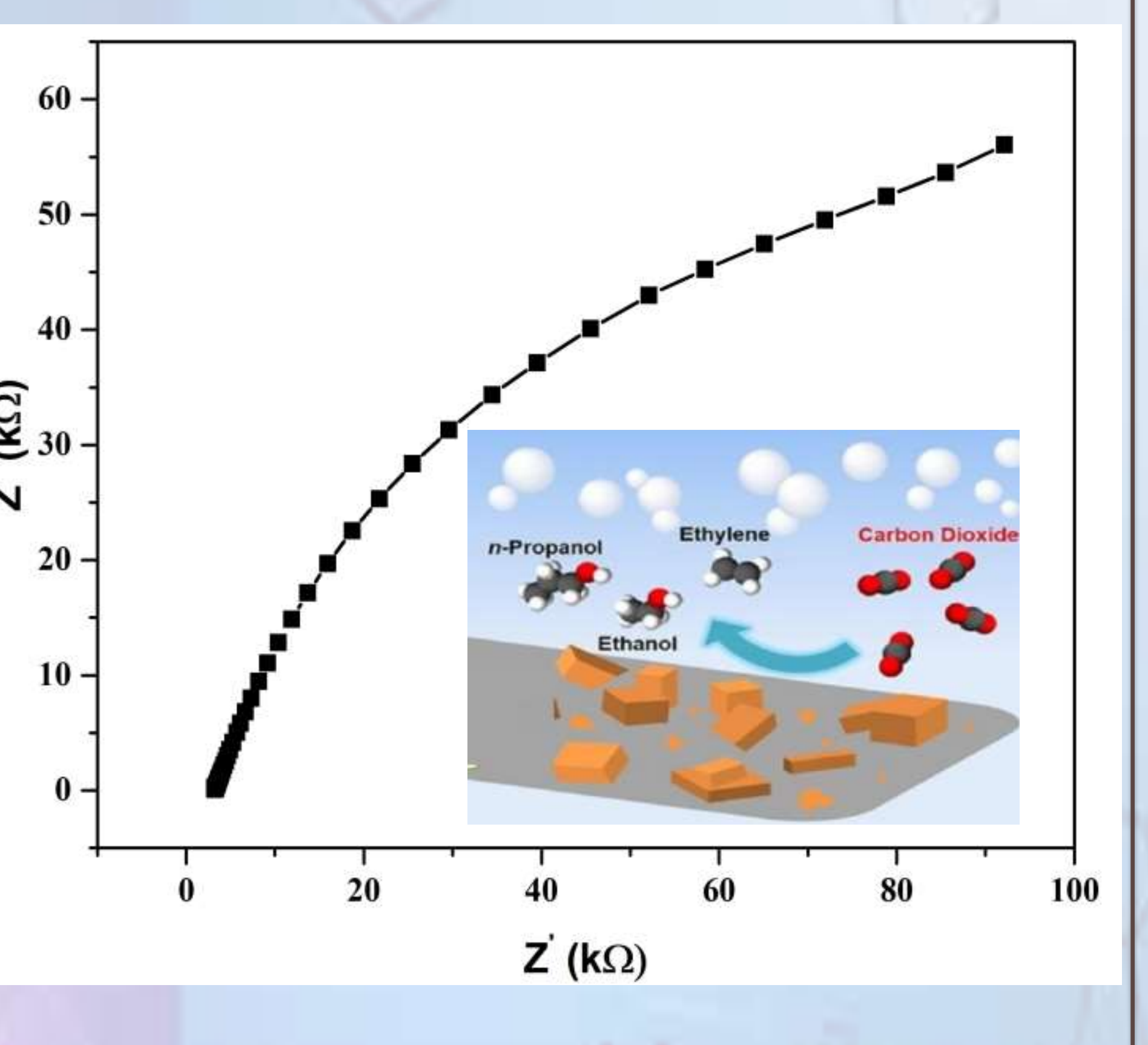

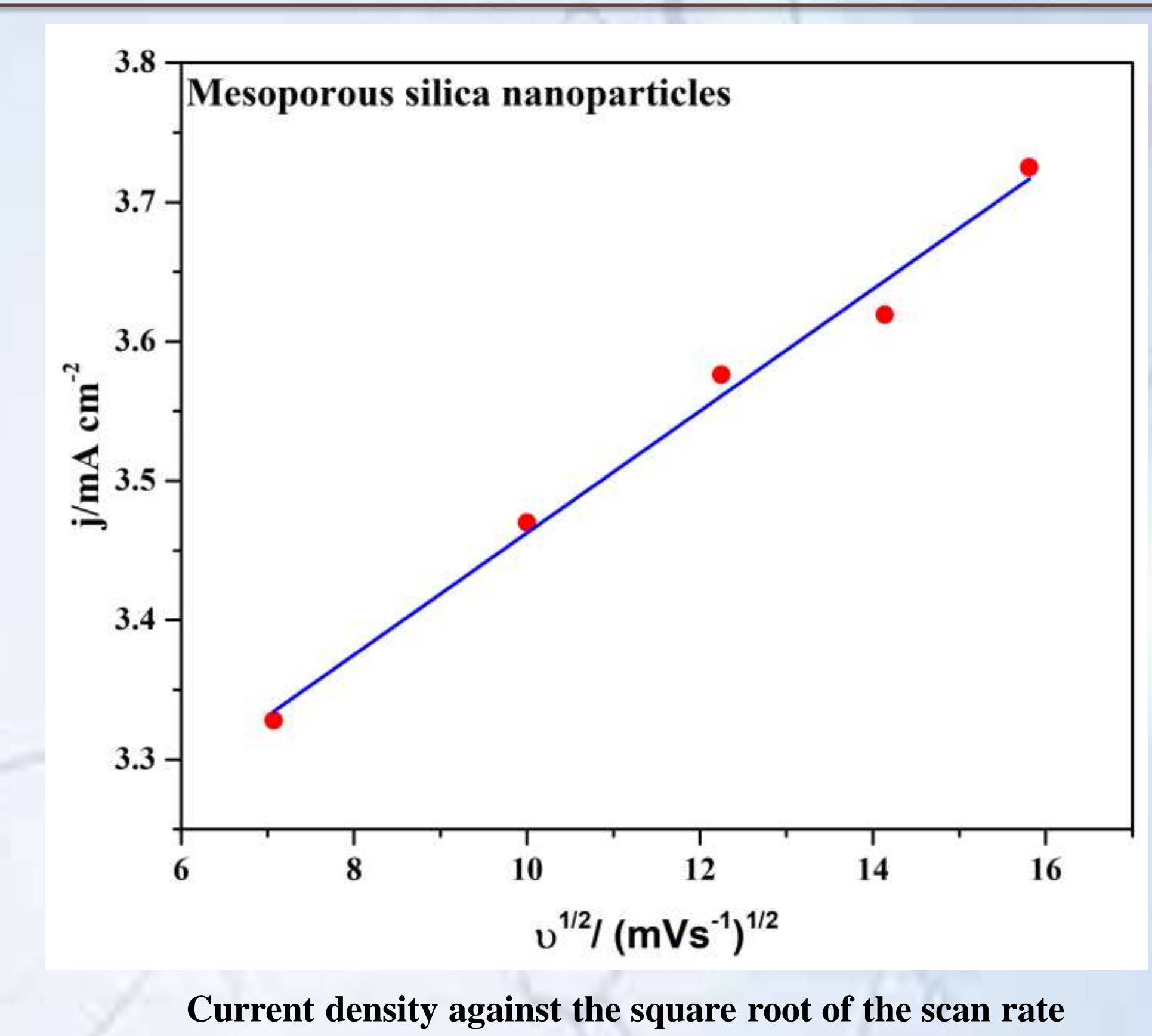

The slope of mesoporous silica nanoparticles is $0.04372 \mathrm{mV}$ dec $^{-1}$ obtained from the Randles-Seveik equation

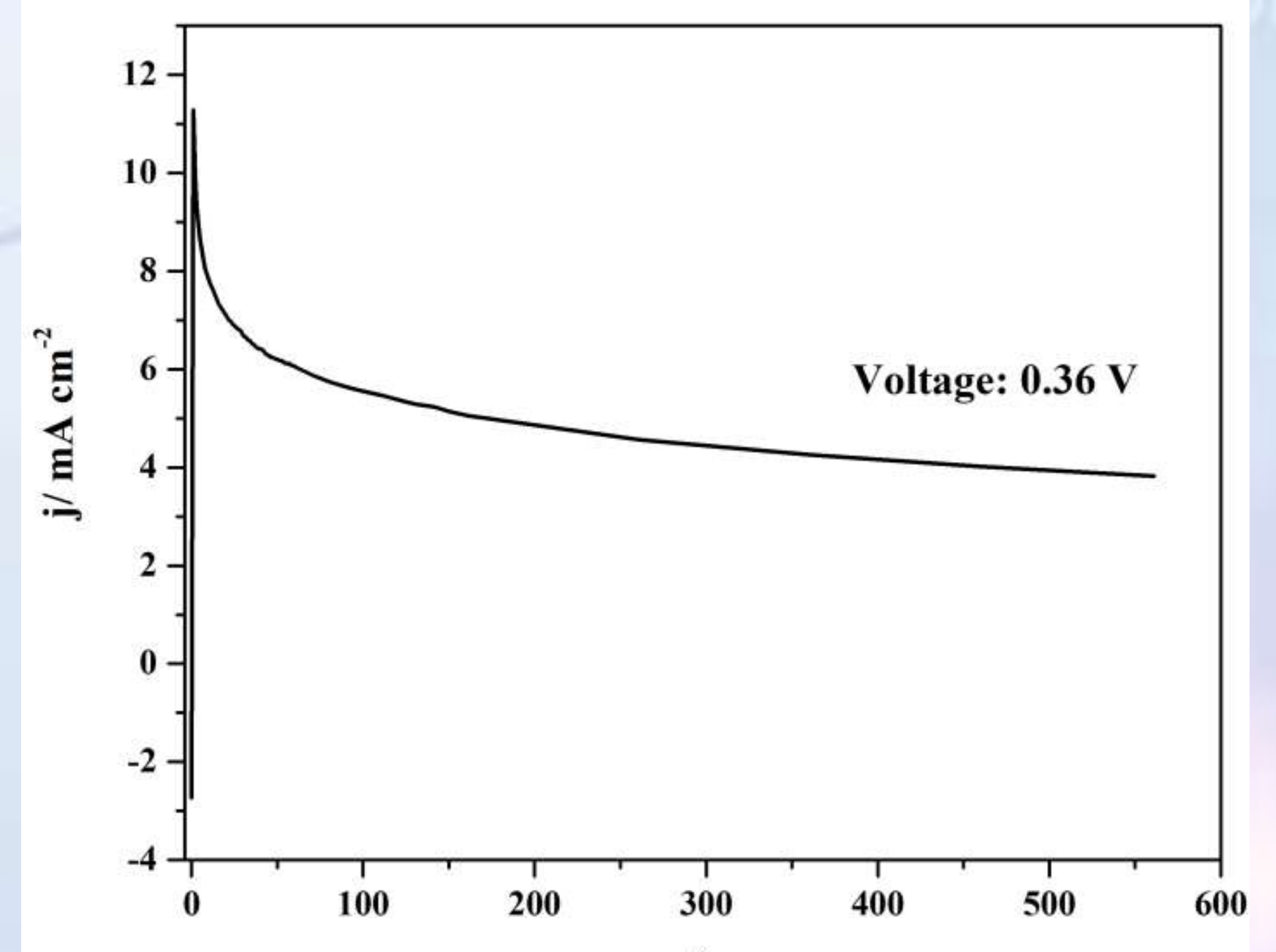

Chronoamperometric measurements at relevant potentials for 10 minutes

\section{BENEFITS TO QATAR}

Qatar has a major petrochemical industry along with other similar manufacturing industries and factories which release carbon dioxide. Thus, to reduce these carbon dioxide emissions from these industries, electrochemical catalytic reduction of $\mathrm{CO}_{2}$ in the presence of the synthesized mesoporous silica nanoparticles can be used.

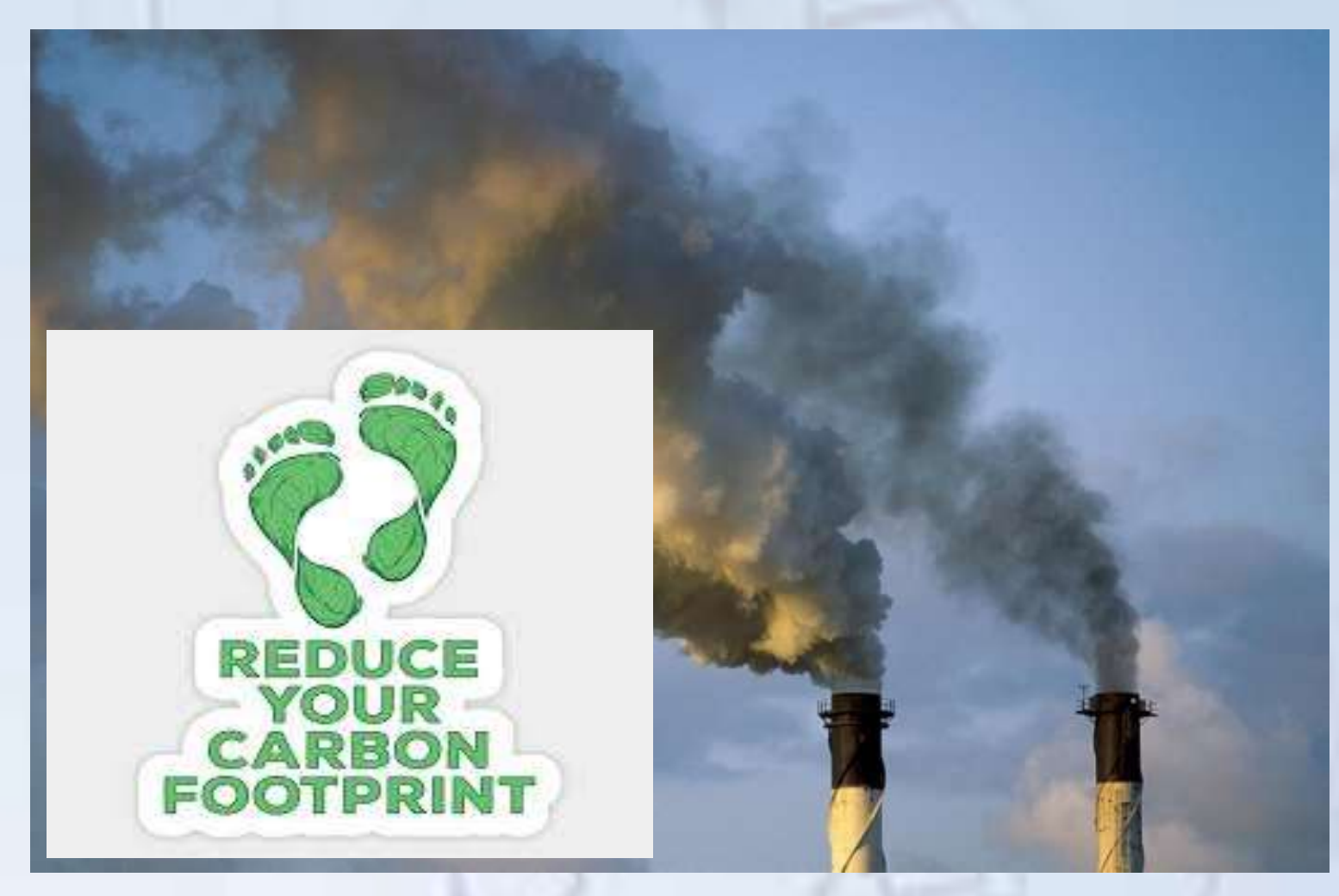

\section{CONCLUSION}

From the different tests, the following properties were shown;

XRD: Mesoporous silica nanoparticlescrystalline periodic system

FTIR: $1056,800,673 \mathrm{~cm}^{-1}$ (Si-O-Si stretching) SEM with EDAX: Formation of mesoporous silica nanoparticles.

Thus, it can be stated that the synthesized mesoporous silica nanoparticles in this research are an appropriate material for electrocatalytic reduction of $\mathrm{CO}_{2}$ to fuel.

\section{ACKNOWLEDGEMENTS}

This work was supported by the NPRP grant \# NPRP11S-1221-170116 from the Qatar National Research Fund (a member of Qatar Foundation). The statements made herein are solely the responsibility of the authors. Thanks also to Central Laboratory Unit, Qatar University, Qatar.

\section{REFERENCES}

Liu, M., Sun, X., Liao, Z., Li, Y., Qi, X., \& Qian, Y. (2019). Zinc oxide end-capped $\mathrm{Fe} 3 \mathrm{O} 4 @ \mathrm{mSiO} 2$ core-shell nanocarriers as targeted and responsive drug delivery system for chemo- / ions synergistic therapeutics. Drug Delivery, 26(1), 732-743.

https://doi.org/10.1080/10717544.2019.1642419 